Article

\title{
Global Metabolomics of the Placenta Reveals Distinct Metabolic Profiles between Maternal and Fetal Placental Tissues Following Delivery in Non-Labored Women
}

\author{
Jacquelyn M. Walejko ${ }^{1}$, Anushka Chelliah ${ }^{2}$, Maureen Keller-Wood ${ }^{3}$, Anthony Gregg ${ }^{4}$ and \\ Arthur S. Edison 5,* (D) \\ 1 Department of Biochemistry \& Molecular Biology, University of Florida, Gainesville, FL 32610, USA; \\ jwalejko@ufl.edu \\ 2 Department of Obstetrics, Gynecology, and Reproductive Sciences, University of Texas Health Science \\ Center at Houston, UT Health, Houston, TX 77030, USA; anushka.chelliah@uth.tmc.edu \\ 3 Department of Pharmacodynamics, University of Florida, Gainesville, FL 32610, USA; kellerwd@cop.ufl.edu \\ 4 Department of Obstetrics and Gynecology, University of Florida, Gainesville, FL 32610, USA; \\ greggar@ufl.edu \\ 5 Departments of Genetics and Biochemistry \& Molecular Biology, Institute of Bioinformatics, \\ Complex Carbohydrate Research Center, University of Georgia, Athens, GA 30602, USA \\ * Correspondence: aedison@uga.edu; Tel.: +1-706-542-8156
}

Received: 17 December 2017; Accepted: 19 January 2018; Published: 23 January 2018

\begin{abstract}
We evaluated the metabolic alterations in maternal and fetal placental tissues from non-labored women undergoing cesarean section using samples collected from $5 \mathrm{~min}$ to $24 \mathrm{~h}$ following delivery. Using ${ }^{1} \mathrm{H}-\mathrm{NMR}$, we identified 14 metabolites that significantly differed between maternal and fetal placental tissues (FDR-corrected $p$-value $<0.05$ ), with 12 metabolites elevated in the maternal tissue, reflecting the flux of these metabolites from mother to fetus. In the maternal tissue, 4 metabolites were significantly altered at $15 \mathrm{~min}, 10$ metabolites at $30 \mathrm{~min}$, and 16 metabolites at $1 \mathrm{~h}$ postdelivery, while 11 metabolites remained stable over $24 \mathrm{~h}$. In contrast, in the fetal placenta tissue, 1 metabolite was significantly altered at $15 \mathrm{~min}, 2$ metabolites at $30 \mathrm{~min}$, and 4 metabolites at $1 \mathrm{~h}$ postdelivery, while 22 metabolites remained stable over $24 \mathrm{~h}$. Our study provides information on the metabolic profiles of maternal and fetal placental tissues delivered by cesarean section and reveals that there are different metabolic alterations in the maternal and fetal tissues of the placenta following delivery.
\end{abstract}

Keywords: pregnancy; human; placenta; metabolomics; ${ }^{1} \mathrm{H}-\mathrm{NMR}$

\section{Introduction}

The placenta is an organ that develops during pregnancy and has numerous functions in the mother and fetus, such as preventing rejection of the fetal allograft, transporting nutrients, eliminating waste products, and enabling gas exchange. Sheep models of pregnancy have found that $40-80 \%$ of all oxygen and glucose that reach the placenta are utilized to produce fructose, nonessential amino acids, and lactate, which are then delivered to the fetus as nutrients [1-7]. However, these metabolic pathways have not been well characterized in the human placenta. Several studies utilized stable isotope tracers in women to determine the flux of various amino acids across the placenta in late gestation prior to delivery [8-11]. In addition, cells from the human placenta revealed a higher propensity for aerobic glycolysis, while metagenomic sequencing from the surface of the placenta revealed a distinct microbiome environment, with several microbes that have metabolic functions in 
the placenta [12,13]. Metabolic pathways of the human placenta were identified by transcriptomic analysis, but the related downstream metabolites have not yet been studied in depth [14,15].

Metabolomics is the study of small molecules in a biological system and has been utilized to study both placental cells and whole placental tissue in pregnancies complicated by disease [16-21]. However, there is little information on how timing and area of collection affect metabolic profiles in placental tissue. The human placenta is made up of two components: a maternal surface that develops from the endometrium and a fetal surface that develops from fetal cells [22]. To date, there is little information on metabolic differences between specimens collected from the maternal or fetal surfaces of the placenta and on whether the stability of metabolites differs between these tissue types as a function of time before extraction. The current data for the optimization of placental specimen collection for metabolomics studies recommends immediate processing of vaginally delivered specimens, within $10 \mathrm{~min}$ of delivery [23]. While this short time is ideal, it poses a significant practical challenge for specimen collection in the delivery room, and the lack of timely processing may result in the loss of useful metabolic data. In addition, the optimal time following delivery to collect specimens for metabolomics studies has not been reported for women that undergo non-labored, cesarean delivery. In this study, we evaluated the differences in metabolites measured in maternal and fetal placental specimens, as well as the changes in these metabolites at various time points from immediate up to $24 \mathrm{~h}$ postdelivery in women undergoing non-labored cesarean deliveries.

\section{Results}

\subsection{Metabolic Alterations between the Maternal and Fetal Surfaces of the Placenta}

Figure 1 shows the normalized proton nuclear magnetic resonance $\left({ }^{1} \mathrm{H}-\mathrm{NMR}\right)$ spectra from maternal (blue) and fetal (red) placental specimens at five time points following delivery, as indicated by shading (light $<5 \mathrm{~min}$ to dark at $24 \mathrm{~h}$ ). The metabolite areas used for quantitation are indicated by green bars under the spectra, while the regions that were not quantified are indicated by grey bars. Orthogonal signal correction-partial least squares discriminant analysis (OSC-PLSDA) revealed a separation between maternal and fetal placental specimens (Figure 2a; Component 1, $R^{2} Y=0.97$, $\mathrm{Q}^{2} \mathrm{Y}=0.56$ ). A principal component analysis (PCA) of the same data showed some separation but was less useful (Supplementary Material Figures S1-S3). At 15 min postdelivery, many metabolites were significantly elevated (FDR-corrected $p<0.05$ ) in maternal placental specimens, including amino acids (serine and threonine), citrate, and choline (Figure 2b, right). Metabolites significantly elevated (FDR-corrected $p<0.05$ ) in fetal placental specimens included very-low-density lipoprotein (VLDL) and formate (Figure $2 \mathrm{~b}$, left). All identified metabolites and their corresponding means with standard errors, FDR-corrected $p$-values, and fold changes are listed in Table 1.

Table 1. Metabolites identified on maternal and fetal surfaces of the placenta at $15 \mathrm{~min}$ postdelivery.

\begin{tabular}{|c|c|c|c|c|}
\hline \multirow{2}{*}{ Metabolite } & \multicolumn{2}{|c|}{ Mean (SE) ${ }^{a}$} & \multirow{2}{*}{$\begin{array}{l}\text { FDR-Corrected } \\
p \text {-Value }\end{array}$} & \multirow{2}{*}{$\begin{array}{l}\text { Fold Change: } \\
\text { Maternal vs. Fetal }\end{array}$} \\
\hline & Maternal & Fetal & & \\
\hline Choline & $3.372(0.113)$ & $2.142(0.165)$ & $3.6 \times 10^{-4}$ & 1.57 \\
\hline Serine & $1.917(0.070)$ & $1.409(0.052)$ & $4.0 \times 10^{-4}$ & 1.36 \\
\hline Threonine & $0.395(0.007)$ & $0.349(0.004)$ & $4.0 \times 10^{-4}$ & 1.13 \\
\hline Citrate & $0.475(0.019)$ & $0.356(0.012)$ & $9.9 \times 10^{-4}$ & 1.34 \\
\hline Glycerol & $0.210(0.008)$ & $0.162(0.006)$ & $4.3 \times 10^{-3}$ & 1.29 \\
\hline Acetate & $0.335(0.008)$ & $0.278(0.010)$ & $5.2 \times 10^{-3}$ & 1.21 \\
\hline Succinate & $0.230(0.011)$ & $0.174(0.007)$ & $8.5 \times 10^{-3}$ & 1.32 \\
\hline Formate & $0.037(0.001)$ & $0.048(0.002)$ & $9.9 \times 10^{-3}$ & 0.78 \\
\hline Aspartate & $0.152(0.003)$ & $0.128(0.006)$ & 0.01 & 1.19 \\
\hline $\mathrm{VLDL}^{\mathrm{b}}$ & $1.333(0.049)$ & $1.593(0.059)$ & 0.03 & 0.84 \\
\hline Taurine & $2.787(0.099)$ & $2.387(0.070)$ & 0.04 & 1.17 \\
\hline Niacinamide & $0.040(0.001)$ & $0.035(0.001)$ & 0.04 & 1.16 \\
\hline Alanine & $1.171(0.029)$ & $1.026(0.037)$ & 0.05 & 1.14 \\
\hline $\mathrm{GPC}^{\mathrm{c}}$ & $2.769(0.207)$ & $1.960(0.160)$ & 0.05 & 1.41 \\
\hline
\end{tabular}


Table 1. Cont.

\begin{tabular}{ccccc}
\hline Metabolite & \multicolumn{2}{c}{ Mean (SE) ${ }^{\mathbf{a}}$} & $\begin{array}{c}\text { FDR-Corrected } \\
\boldsymbol{p} \text {-Value }\end{array}$ & $\begin{array}{c}\text { Fold Change: } \\
\text { Maternal vs. Fetal }\end{array}$ \\
\cline { 2 - 3 } & Maternal & Fetal & & \\
PC & $0.987(0.034)$ & $0.847(0.036)$ & 0.07 & 1.17 \\
Uridine & $0.056(0.009)$ & $0.031(0.004)$ & 0.12 & 1.79 \\
Fumarate & $0.009(0.001)$ & $0.011(0.001)$ & 0.20 & 0.79 \\
Glutamine & $0.710(0.018)$ & $0.652(0.021)$ & 0.20 & 1.09 \\
Creatine & $0.519(0.027)$ & $0.679(0.075)$ & 0.21 & 0.76 \\
Glucose & $0.826(0.033)$ & $0.948(0.050)$ & 0.21 & 0.87 \\
Uracil & $0.058(0.002)$ & $0.050(0.004)$ & 0.24 & 1.15 \\
3-HB e & $0.321(0.021)$ & $0.392(0.032)$ & 0.25 & 0.82 \\
Asparagine & $0.251(0.004)$ & $0.261(0.003)$ & 0.29 & 0.96 \\
Myo-inositol & $1.520(0.050)$ & $1.378(0.068)$ & 0.29 & 1.10 \\
Glycine & $0.653(0.020)$ & $0.599(0.030)$ & 0.37 & 1.09 \\
Inosine & $0.034(0.006)$ & $0.025(0.002)$ & 0.38 & 1.37 \\
Glutamate & $1.933(0.049)$ & $1.839(0.053)$ & 0.40 & 1.05 \\
Histidine & $0.080(0.002)$ & $0.076(0.002)$ & 0.40 & 1.05 \\
Acetone & $0.102(0.004)$ & $0.093(0.006)$ & 0.41 & 1.10 \\
Leucine & $1.057(0.022)$ & $0.995(0.047)$ & 0.43 & 1.06 \\
Lactate & $10.632(0.411)$ & $10.033(0.427)$ & 0.52 & 1.06 \\
Valine & $0.467(0.012)$ & $0.448(0.015)$ & 0.53 & 1.04 \\
Tyrosine & $0.118(0.003)$ & $0.123(0.005)$ & 0.63 & 0.96 \\
Phenylalanine & $0.536(0.011)$ & $0.548(0.021)$ & 0.79 & 0.98 \\
Hypoxanthine & $0.268(0.007)$ & $0.271(0.009)$ & 0.88 & 0.99 \\
Glutathione & $0.104(0.005)$ & $0.102(0.005)$ & 0.88 & 1.02 \\
Lysine & $0.390(0.008)$ & $0.387(0.012)$ & 0.90 & 1.01 \\
Isoleucine & $0.232(0.005)$ & $0.231(0.007)$ & 0.93 & 1.00 \\
\hline
\end{tabular}

${ }^{a}$ Means and standard error (SE) were calculated after normalization; ${ }^{b}$ VLDL: Very-low-density lipoprotein; ${ }^{c}$ GPC: Glycerophosphocholine; ${ }^{\mathrm{d}}$ PC: Phosphocholine. ${ }^{\mathrm{e}}$ 3-HB: 3-hydroxybutyrate.

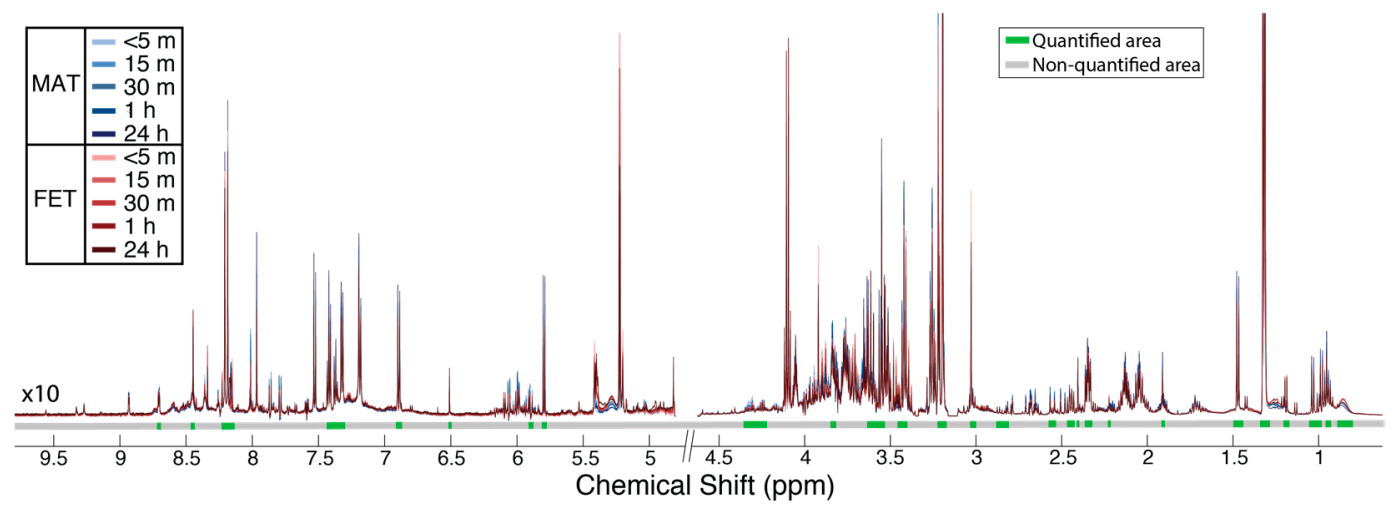

Figure 1. Overlay of mean ${ }^{1} \mathrm{H}-\mathrm{NMR}$ spectra from five time points following placenta delivery: $(1)<5 \mathrm{~min}(n=24),(2) 15 \mathrm{~min}(n=49),(3) 30 \mathrm{~min}(n=51),(4) 1 \mathrm{~h}(n=51)$, and (5) $24 \mathrm{~h}(n=51)$. Maternal spectra (MAT) are displayed in blue, while fetal (FET) spectra are displayed in red. Metabolite identification was conducted using 2D NMR data (HSQC and HSQC-TOCSY), using COLMARm and Bruker Assure software. Non-overlapped peaks for the identified metabolites $(n=38)$ are shown in green under the spectra, while areas not quantified are displayed in gray. The negative tails of peaks seen around some resonances are from Carr-Purcell-Meiboom-Gill (CPMG) pulse sequence artifacts arising from antiphase coherence. 

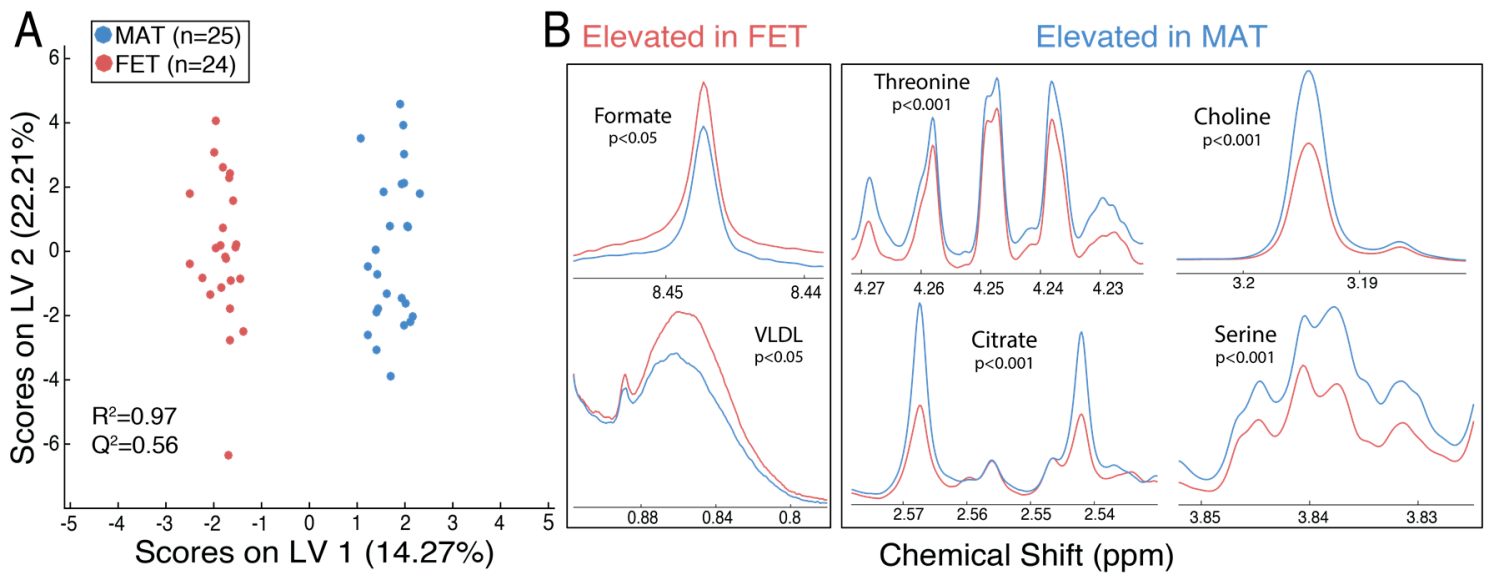

Figure 2. (A) Orthogonal signal correction-partial least squares discriminant analysis (OSC-PLSDA) scores plot reveals a separation of MAT (blue, $n=25$ ) and FET (red, $n=24$ ) spectra from 13 placentas at 15 min postdelivery; (B) the mean spectra of FET (red) and MAT (blue) display significant (FDR-corrected $p<0.05$ ) elevations in formate and VLDL in fetal placental specimens (left), while threonine, choline, citrate, and serine are significantly elevated in the maternal tissue (right). Table 1 displays the means with standard errors, FDR-corrected p-value, and fold change for all metabolites identified.

\subsection{The Maternal Surface of the Placenta Reveals Metabolites That Are Sensitive to the Timing of Collection Following Delivery}

Partial least squares discriminant analysis (PLS-DA) revealed separation of the maternal placental specimens based on the time following delivery (Figure 3a). A one-way analysis of variance (ANOVA) revealed that anaerobic glycolysis (elevations in lactate, diminished glucose) occurred within $15 \mathrm{~min}$ following delivery, while glutamate and hypoxanthine displayed alterations $1 \mathrm{~h}$ and $24 \mathrm{~h}$, respectively, following delivery (FDR-corrected $p<0.05$ ). Some metabolites, including taurine and creatine, did not display significant metabolic alterations up to $24 \mathrm{~h}$ following delivery in maternal placental specimens (Figure 3b). All metabolites identified in the maternal tissue and their corresponding means with standard errors, FDR-corrected $p$-values, and fold changes over $1 \mathrm{~h}$ following delivery are displayed in Table 2. The relative trends for metabolites over $1 \mathrm{~h}$ are displayed in Figure S4. Lactate and various amino acids displayed a linear increase over time (Figure S4a), while glycerophosphocholine (GPC), glucose, niacinamide, and formate displayed a linear decrease over time (Figure S4b). The results of Tukey-Kramer post-hoc analysis for each metabolite in the maternal placental tissue are displayed in Table S2.

Table 2. Metabolites abundance over $24 \mathrm{~h}$ on the surface of the maternal placenta.

\begin{tabular}{|c|c|c|c|c|c|c|c|}
\hline \multirow{2}{*}{ Metabolite } & \multicolumn{5}{|c|}{ Mean (SE) ${ }^{a}$} & \multirow{2}{*}{$\begin{array}{c}\text { FDR-Corrected } \\
p \text {-Value }\end{array}$} & \multirow{2}{*}{$\begin{array}{c}\text { Fold Change } \\
\text { over } 1 \mathrm{~h}\end{array}$} \\
\hline & $<5$ min & $15 \mathrm{~min}$ & $30 \mathrm{~min}$ & $1 \mathrm{~h}$ & $24 \mathrm{~h}$ & & \\
\hline Glycerol & $0.147(0.021)$ & $0.210(0.014)$ & $0.235(0.014)$ & $0.302(0.014)$ & $0.514(0.014)$ & $2.03 \times 10^{-31}$ & 2.06 \\
\hline Choline & $2.558(0.297)$ & $3.372(0.206)$ & $3.840(0.202)$ & $4.459(0.202)$ & $5.845(0.202)$ & $1.41 \times 10^{-15}$ & 1.74 \\
\hline $\mathrm{GPC}^{\mathrm{b}}$ & $4.363(0.318)$ & $2.769(0.220)$ & $2.763(0.216)$ & $2.395(0.216)$ & $1.174(0.216)$ & $8.25 \times 10^{-11}$ & 0.55 \\
\hline Glucose & $1.031(0.059)$ & $0.826(0.041)$ & $0.773(0.040)$ & $0.741(0.040)$ & $0.472(0.040)$ & $8.48 \times 10^{-11}$ & 0.72 \\
\hline Uracil & $0.058(0.009)$ & $0.058(0.006)$ & $0.063(0.006)$ & $0.072(0.006)$ & $0.112(0.006)$ & $1.81 \times 10^{-8}$ & 1.25 \\
\hline Formate & $0.046(0.003)$ & $0.037(0.002)$ & $0.035(0.002)$ & $0.030(0.002)$ & $0.026(0.002)$ & $1.81 \times 10^{-8}$ & 0.66 \\
\hline Tyrosine & $0.112(0.009)$ & $0.118(0.006)$ & $0.127(0.006)$ & $0.141(0.006)$ & $0.164(0.006)$ & $8.43 \times 10^{-7}$ & 1.26 \\
\hline Phenylalanine & $0.506(0.032)$ & $0.536(0.022)$ & $0.563(0.022)$ & $0.615(0.022)$ & $0.699(0.022)$ & $1.49 \times 10^{-6}$ & 1.22 \\
\hline Isoleucine & $0.209(0.013)$ & $0.232(0.009)$ & $0.244(0.009)$ & $0.265(0.009)$ & $0.292(0.009)$ & $4.20 \times 10^{-6}$ & 1.27 \\
\hline Leucine & $0.925(0.070)$ & $1.057(0.048)$ & $1.117(0.048)$ & $1.237(0.048)$ & $1.346(0.048)$ & $1.23 \times 10^{-5}$ & 1.34 \\
\hline
\end{tabular}


Table 2. Cont.

\begin{tabular}{|c|c|c|c|c|c|c|c|}
\hline \multirow{2}{*}{ Metabolite } & \multicolumn{5}{|c|}{ Mean (SE) ${ }^{a}$} & \multirow{2}{*}{$\begin{array}{c}\text { FDR-Corrected } \\
p \text {-Value }\end{array}$} & \multirow{2}{*}{$\begin{array}{c}\text { Fold Change } \\
\text { over } 1 \mathrm{~h}\end{array}$} \\
\hline & $<5 \mathrm{~min}$ & $15 \mathrm{~min}$ & $30 \mathrm{~min}$ & $1 \mathrm{~h}$ & $24 \mathrm{~h}$ & & \\
\hline Citrate & $0.421(0.028)$ & $0.475(0.019)$ & $0.487(0.019)$ & $0.450(0.019)$ & $0.360(0.019)$ & $9.97 \times 10^{-5}$ & 1.07 \\
\hline Glutamine & $0.615(0.029)$ & $0.710(0.020)$ & $0.739(0.020)$ & $0.756(0.020)$ & $0.707(0.020)$ & $4.71 \times 10^{-3}$ & 1.23 \\
\hline Threonine & $0.381(0.009)$ & $0.395(0.006)$ & $0.393(0.006)$ & $0.388(0.006)$ & $0.364(0.006)$ & 0.01 & 1.02 \\
\hline Glutathione & $0.085(0.009)$ & $0.104(0.006)$ & $0.114(0.006)$ & $0.099(0.006)$ & $0.086(0.006)$ & 0.01 & 1.16 \\
\hline Niacinamide & $0.048(0.002)$ & $0.040(0.001)$ & $0.039(0.001)$ & $0.040(0.001)$ & $0.042(0.001)$ & 0.03 & 0.84 \\
\hline VLDL $^{d}$ & $1.293(0.097)$ & $1.333(0.067)$ & $1.250(0.066)$ & $1.225(0.066)$ & $1.033(0.066)$ & 0.04 & 0.95 \\
\hline Histidine & $0.075(0.005)$ & $0.080(0.003)$ & $0.078(0.003)$ & $0.083(0.003)$ & $0.068(0.003)$ & 0.04 & 1.11 \\
\hline Myo-inositol & $1.521(0.081)$ & $1.520(0.056)$ & $1.568(0.055)$ & $1.559(0.055)$ & $1.342(0.055)$ & 0.04 & 1.02 \\
\hline Glutamate & $1.820(0.089)$ & $1.933(0.062)$ & $2.001(0.061)$ & $2.123(0.061)$ & $2.080(0.061)$ & $<0.05$ & 1.17 \\
\hline Taurine & $2.803(0.141)$ & $2.787(0.098)$ & $2.792(0.096)$ & $2.844(0.096)$ & $2.549(0.096)$ & 0.25 & 1.02 \\
\hline Fumarate & $0.008(0.001)$ & $0.009(0.001)$ & $0.009(0.001)$ & $0.009(0.001)$ & $0.011(0.001)$ & 0.29 & 1.11 \\
\hline Asparagine & $0.259(0.008)$ & $0.251(0.005)$ & $0.259(0.005)$ & $0.265(0.005)$ & $0.263(0.005)$ & 0.44 & 1.03 \\
\hline Uridine & $0.050(0.010)$ & $0.056(0.007)$ & $0.040(0.007)$ & $0.042(0.007)$ & $0.041(0.007)$ & 0.44 & 0.84 \\
\hline Creatine & $0.560(0.043)$ & $0.519(0.030)$ & $0.500(0.029)$ & $0.513(0.029)$ & $0.535(0.029)$ & 0.82 & 0.92 \\
\hline $3-\mathrm{HB}^{\mathrm{e}}$ & $0.297(0.042)$ & $0.321(0.029)$ & $0.320(0.029)$ & $0.306(0.029)$ & $0.318(0.029)$ & 0.99 & 1.03 \\
\hline
\end{tabular}

${ }^{a}$ Means and standard error (SE) were calculated after normalization; ${ }^{b}$ GPC: Glycerophosphocholine; ${ }^{c}$ PC: Phosphocholine; ${ }^{\mathrm{d}}$ VLDL: Very-low-density lipoprotein; ${ }^{\mathrm{e}}$ 3-HB: 3-hydroxybutyrate.
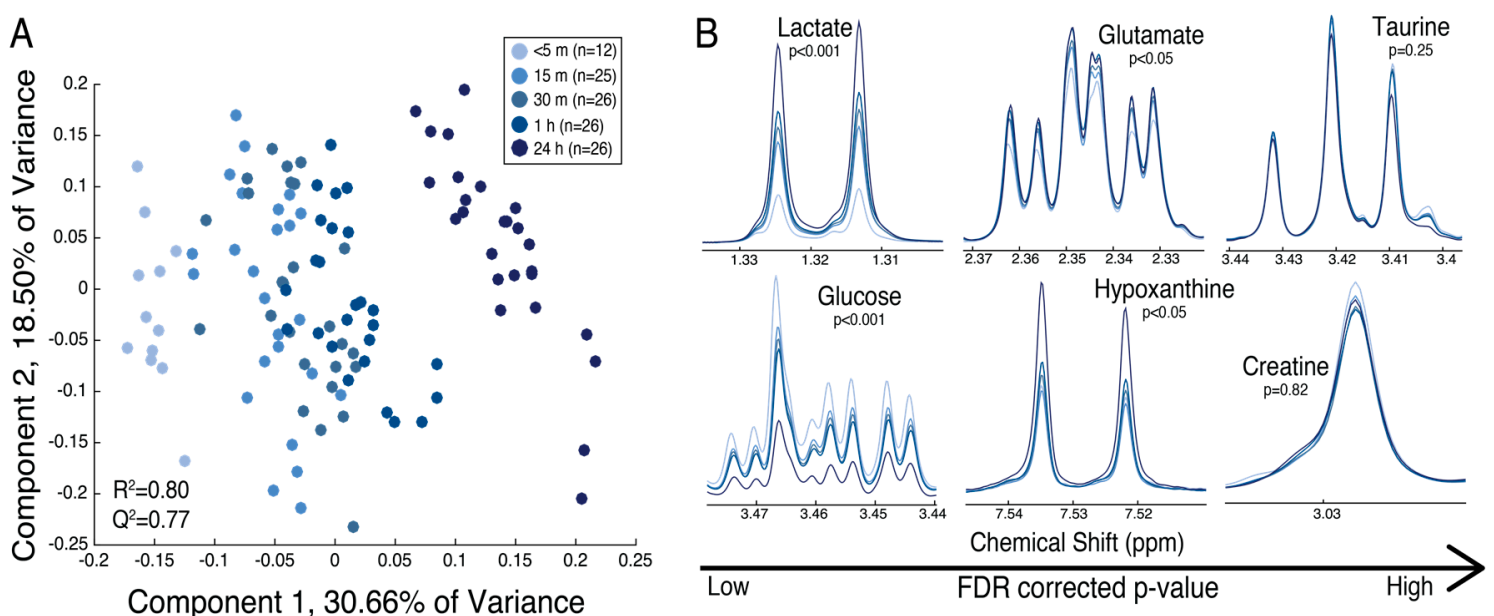

Figure 3. (A) The partial least squares discriminant analysis (PLS-DA) scores plot reveals separation of the specimens from the maternal surface of 13 placentas at five time points postdelivery: $(1)<5 \mathrm{~min}$ $(n=12),(2) 15 \mathrm{~min}(n=25),(3) 30 \mathrm{~min}(n=26),(4) 1 \mathrm{~h}(n=26)$, and (5) $24 \mathrm{~h}(n=26)$. The time points are represented as varying shades of blue, from light $(<5 \mathrm{~min})$ to dark $(24 \mathrm{~h})$; (B) mean spectra of time points displaying metabolites with varying significance of FDR-corrected $\mathrm{p}$-values from left to right (low to high). Lactate significantly increased over time $(p<0.001)$, while glucose diminished $(p<0.001)$. Glutamate and hypoxanthine significantly increased over time $(p<0.05)$, while taurine and creatine did not differ over $24 \mathrm{~h}$. Table 2 displays means with standard errors, FDR-corrected p-value, and fold change between $<5 \mathrm{~min}$ and $1 \mathrm{~h}$ following delivery for all metabolites identified.

\subsection{The Fetal Surface of the Placenta Shows Less Sensitivity to Timing of Collection Following Delivery}

PLS-DA revealed separation of the fetal placental specimens based on the time of collection following delivery (Figure $4 \mathrm{a}$, left). This separation is not as distinct as that found in maternal placental specimens, as indicated by the poorer model quality $\left(\mathrm{Q}^{2}\right.$ of 0.58 in fetal compared to $\mathrm{Q}^{2}$ of 0.88 in maternal). One-way ANOVA revealed significant elevations (FDR-corrected $p<0.05$ ) in lactate within 
$30 \mathrm{~min}$ and choline within $1 \mathrm{~h}$ following delivery, while uracil was significantly elevated $24 \mathrm{~h}$ following delivery. Phenylalanine, acetate, and valine were not significantly altered over time (Figure 4b, right). All metabolites identified in the fetal tissue and their corresponding means with standard errors, FDR-corrected p-value, and fold change over $1 \mathrm{~h}$ are displayed in Table 3 . The relative trends for metabolites over $1 \mathrm{~h}$ are displayed in Figure S5. Similar to the maternal placental metabolite trends, lactate and choline displayed a linear increase over time (Figure S5a), while the storage form of cholines (PC and GPC) and niacinaminde displayed a linear decrease over time (Figure S5b). The results of Tukey-Kramer post-hoc analysis for each metabolite in the fetal placental tissue are displayed in Table S3.
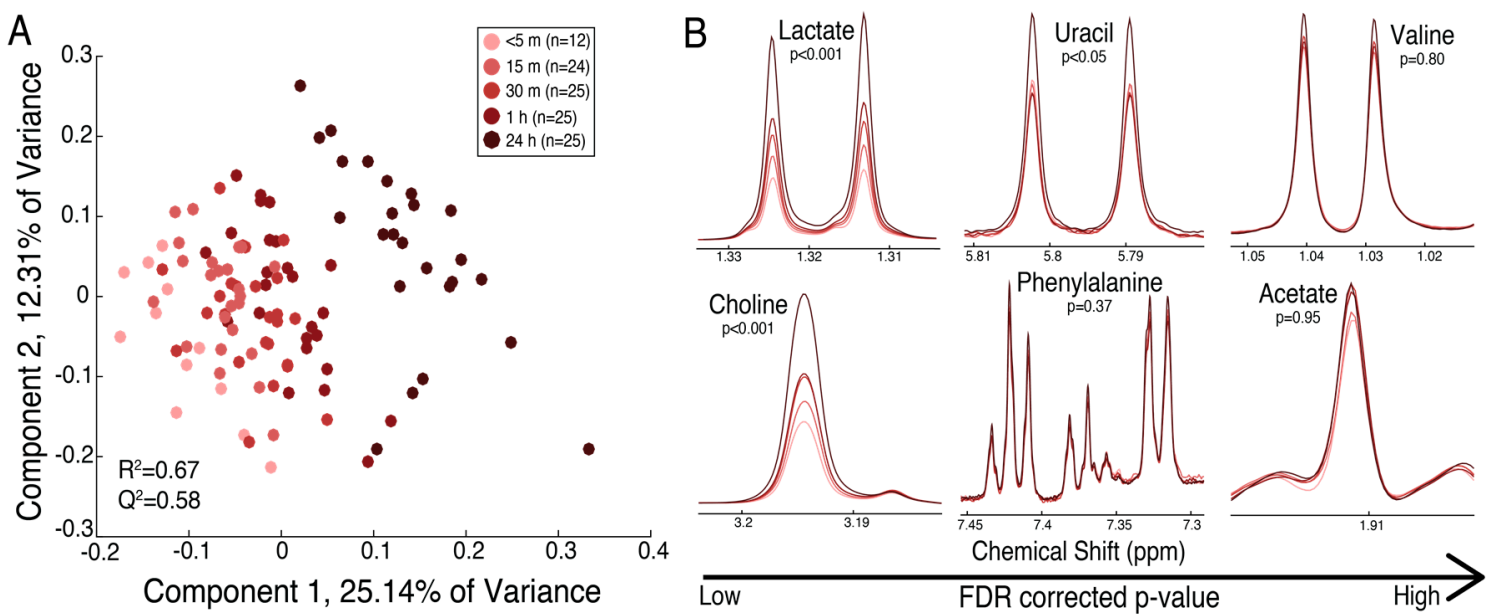

Figure 4. (A) The PLS-DA scores plot reveals separation of the specimens from the fetal surface of the placenta from 13 placentas at five time points postdelivery: $(1)<5 \min (n=12),(2) 15 \min (n=24)$, (3) $30 \mathrm{~min}(n=25),(4) 1 \mathrm{~h}(n=25)$, and (5) $24 \mathrm{~h}(n=25)$. The time points are represented as varying shades of red, from light $(<5 \mathrm{~min})$ to dark $(24 \mathrm{~h}) ;($ B $)$ mean spectra of time points displaying metabolites with varying significance of FDR-corrected $p$-values from left to right (low to high). Lactate, choline, and uracil significantly increased over time $(p<0.001)$, while phenylalanine, valine, and acetate did not show a significant trend over $24 \mathrm{~h}$. Table 3 displays the means with standard errors, FDR-corrected $p$-value, and fold change between $<5 \mathrm{~min}$ and $1 \mathrm{~h}$ following delivery for all metabolites identified.

Table 3. Metabolites abundance over $24 \mathrm{~h}$ on the surface of the fetal placenta.

\begin{tabular}{|c|c|c|c|c|c|c|c|}
\hline \multirow{2}{*}{ Metabolite } & \multicolumn{5}{|c|}{ Mean (SE) ${ }^{a}$} & \multirow{2}{*}{$\begin{array}{c}\text { FDR-Corrected } \\
p \text {-Value }\end{array}$} & \multirow{2}{*}{$\begin{array}{c}\text { Fold Change } \\
\text { over } 1 \mathrm{~h}\end{array}$} \\
\hline & $<5 \mathrm{~min}$ & $15 \mathrm{~min}$ & $30 \mathrm{~min}$ & $1 \mathrm{~h}$ & $24 \mathrm{~h}$ & & \\
\hline Glycerol & $0.140(0.019)$ & $0.162(0.013)$ & $0.184(0.013)$ & $0.193(0.013)$ & $0.381(0.013)$ & $4.4 \times 10^{-22}$ & 1.38 \\
\hline Choline & $1.730(0.282)$ & $2.142(0.200)$ & $2.594(0.196)$ & $2.683(0.196)$ & $4.158(0.196)$ & $1.5 \times 10^{-10}$ & 1.55 \\
\hline$P C^{b}$ & $1.089(0.069)$ & $0.847(0.049)$ & $0.886(0.048)$ & $0.891(0.048)$ & $0.589(0.048)$ & $2.6 \times 10^{-6}$ & 0.82 \\
\hline $\mathrm{GPC}^{\mathrm{c}}$ & $2.443(0.221)$ & $1.960(0.157)$ & 1.949 (0.153) & $1.640(0.153)$ & $0.980(0.153)$ & $7.7 \times 10^{-6}$ & 0.67 \\
\hline Citrate & $0.363(0.021)$ & $0.356(0.015)$ & $0.380(0.014)$ & $0.389(0.014)$ & $0.296(0.014)$ & $5.9 \times 10^{-4}$ & 1.07 \\
\hline Uracil & $0.052(0.006)$ & $0.050(0.004)$ & $0.049(0.004)$ & $0.049(0.004)$ & $0.071(0.004)$ & $4.4 \times 10^{-3}$ & 0.94 \\
\hline Fumarate & $0.010(0.001)$ & $0.011(0.001)$ & $0.011(0.001)$ & $0.012(0.001)$ & $0.016(0.001)$ & $6.3 \times 10^{-3}$ & 1.20 \\
\hline Glycine & $0.605(0.042)$ & $0.599(0.030)$ & $0.616(0.029)$ & $0.607(0.029)$ & $0.735(0.029)$ & 0.02 & 1.00 \\
\hline Glutathione & $0.092(0.008)$ & $0.102(0.006)$ & $0.100(0.006)$ & $0.107(0.006)$ & $0.080(0.006)$ & 0.04 & 1.17 \\
\hline Niacinamide & $0.040(0.002)$ & $0.035(0.001)$ & $0.033(0.001)$ & $0.034(0.001)$ & $0.037(0.001)$ & 0.04 & 0.83 \\
\hline VLDL $^{d}$ & $1.527(0.114)$ & $1.593(0.081)$ & $1.528(0.079)$ & $1.491(0.079)$ & $1.279(0.079)$ & 0.16 & 0.98 \\
\hline Glutamate & $1.949(0.100)$ & $1.839(0.071)$ & $1.924(0.069)$ & $1.920(0.069)$ & 1.693 (0.069) & 0.19 & 0.98 \\
\hline Taurine & $2.638(0.136)$ & $2.387(0.096)$ & $2.478(0.094)$ & $2.271(0.094)$ & $2.269(0.094)$ & 0.25 & 0.86 \\
\hline Isoleucine & $0.216(0.010)$ & $0.231(0.007)$ & $0.226(0.007)$ & $0.229(0.007)$ & $0.244(0.007)$ & 0.29 & 1.06 \\
\hline Alanine & $1.052(0.061)$ & $1.026(0.043)$ & $1.030(0.042)$ & $1.044(0.042)$ & $1.156(0.042)$ & 0.29 & 0.99 \\
\hline
\end{tabular}


Table 3. Cont.

\begin{tabular}{|c|c|c|c|c|c|c|c|}
\hline \multirow{2}{*}{ Metabolite } & \multicolumn{5}{|c|}{ Mean (SE) ${ }^{a}$} & \multirow{2}{*}{$\begin{array}{c}\text { FDR-Corrected } \\
p \text {-Value }\end{array}$} & \multirow{2}{*}{$\begin{array}{c}\text { Fold Change } \\
\text { over } 1 \mathrm{~h}\end{array}$} \\
\hline & $<5 \mathrm{~min}$ & $15 \mathrm{~min}$ & $30 \mathrm{~min}$ & $1 \mathrm{~h}$ & $24 \mathrm{~h}$ & & \\
\hline Creatine & $0.997(0.126)$ & $0.679(0.089)$ & $0.620(0.087)$ & $0.700(0.087)$ & $0.776(0.087)$ & 0.29 & 0.70 \\
\hline Hypoxanthine & $0.294(0.016)$ & $0.271(0.011)$ & $0.248(0.011)$ & $0.272(0.011)$ & $0.274(0.011)$ & 0.29 & 0.92 \\
\hline Phenylalanine & $0.535(0.025)$ & $0.548(0.018)$ & $0.511(0.018)$ & $0.520(0.018)$ & $0.563(0.018)$ & 0.37 & 0.97 \\
\hline Formate & $0.053(0.006)$ & $0.048(0.004)$ & $0.047(0.004)$ & $0.054(0.004)$ & $0.043(0.004)$ & 0.51 & 1.03 \\
\hline Tyrosine & $0.124(0.007)$ & $0.123(0.005)$ & $0.117(0.005)$ & $0.117(0.005)$ & $0.129(0.005)$ & 0.60 & 0.94 \\
\hline Glutamine & $0.683(0.033)$ & $0.652(0.023)$ & $0.687(0.023)$ & $0.707(0.023)$ & $0.662(0.023)$ & 0.67 & 1.03 \\
\hline Lysine & $0.379(0.019)$ & $0.387(0.013)$ & $0.360(0.013)$ & $0.358(0.013)$ & $0.369(0.013)$ & 0.67 & 0.95 \\
\hline Uridine & $0.025(0.008)$ & $0.031(0.006)$ & $0.040(0.006)$ & $0.035(0.006)$ & $0.031(0.006)$ & 0.75 & 1.43 \\
\hline Valine & $0.451(0.024)$ & $0.448(0.017)$ & $0.449(0.017)$ & $0.444(0.017)$ & $0.476(0.017)$ & 0.80 & 0.98 \\
\hline Serine & $1.484(0.100)$ & $1.409(0.071)$ & $1.490(0.069)$ & 1.359 (0.069) & $1.458(0.069)$ & 0.80 & 0.92 \\
\hline Inosine & $0.022(0.007)$ & $0.025(0.005)$ & $0.033(0.005)$ & $0.029(0.005)$ & $0.031(0.005)$ & 0.80 & 1.33 \\
\hline Histidine & $0.076(0.004)$ & $0.076(0.003)$ & $0.074(0.003)$ & $0.073(0.003)$ & $0.071(0.003)$ & 0.87 & 0.97 \\
\hline Leucine & $0.937(0.057)$ & $0.995(0.040)$ & $0.950(0.039)$ & $0.944(0.039)$ & $0.991(0.039)$ & 0.88 & 1.01 \\
\hline $3-\mathrm{HB}^{\mathrm{e}}$ & $0.417(0.066)$ & $0.392(0.047)$ & $0.432(0.046)$ & $0.438(0.046)$ & $0.402(0.046)$ & 0.95 & 1.05 \\
\hline Acetate & $0.271(0.016)$ & $0.278(0.012)$ & $0.287(0.011)$ & $0.284(0.011)$ & $0.284(0.011)$ & 0.95 & 1.05 \\
\hline Aspartate & $0.122(0.009)$ & $0.128(0.006)$ & $0.128(0.006)$ & $0.127(0.006)$ & $0.123(0.006)$ & 0.95 & 1.04 \\
\hline Myo-inositol & $1.363(0.144)$ & $1.378(0.102)$ & $1.475(0.100)$ & $1.466(0.100)$ & $1.429(0.100)$ & 0.95 & 1.08 \\
\hline
\end{tabular}

${ }^{a}$ Means and standard error (SE) were calculated after normalization; b PC: Phosphocholine; ${ }^{c}$ GPC:

Glycerophosphocholine; ${ }^{d}$ VLDL: Very-low-density lipoprotein; ${ }^{\mathrm{e}}$ 3-HB: 3-hydroxybutyrate.

\section{Discussion}

We showed that the maternal and fetal sides of the placenta are metabolically distinct. The concentrations of amino acids, including serine, threonine, aspartate, taurine, and alanine, were greater on the maternal-relative to the fetal—side of the placenta. Serine, alanine, taurine and threonine are all metabolites that readily cross the placenta from the maternal circulation in humans and sheep [6,8]. Aspartate was not shown previously to readily cross the human placenta [24], but evidence in sheep suggests small rates of transfer across the placenta [6]. In addition, previous metabolomic studies reported the presence of aspartate in the term, human placenta [21,23]. Choline and GPC, the most abundant storage form of choline, were also increased in the maternal placental tissue, consistent with evidence of transport across the placenta from the maternal circulation [25]. In addition, we found that tricarboxylic acid (TCA) cycle intermediates, including citrate, succinate, and acetate, were elevated in the maternal placental tissue. TCA cycle metabolism occurs in the human placenta, as evidenced by the study of placental mitochondria [26,27]. However, it is unknown in both humans and sheep if the TCA cycle intermediates measured in these studies are delivered to the placenta by the mother or produced in the placental tissue. Still, metabolomics studies identified the presence of TCA cycle intermediates in maternal blood prior to delivery, with citrate increasing throughout gestation, suggesting increased transport to the placenta and fetus [28,29].

VLDL and formate were the only detected features that were significantly more abundant in the fetal placental tissue. VLDLs have been found in human cord blood of term infants and are important in lung surfactant stimulation [30-33]. Formate is important in the placental synthesis of folate, a vitamin involved in DNA replication and required for healthy fetal development [34]. Recent studies in sheep found higher levels of formate in the fetus and amniotic fluid than in the maternal circulation, suggesting production by the placenta or fetus itself [35]. Therefore, the elevation of these metabolites in the fetal placental tissue could indicate their importance in maintaining a healthy pregnancy during late gestation.

In this study, we also measured the stability of amino acids and TCA cycle intermediates in placental tissue up to $24 \mathrm{~h}$ following delivery in non-labored women undergoing cesarean delivery. In both maternal and fetal tissues, amino acids, TCA cycle intermediates, choline and choline derivatives, formate, and niacinamide changed in concentration within $1 \mathrm{~h}$ following delivery. As discussed above, amino acids, TCA cycle intermediates, and formate have all been shown to be important metabolic substrates for both the placenta and the fetus. Choline is an important substrate in cellular membrane formation and neurodevelopment in the fetus [36,37]. Our data suggest 
that, similar to other tissues, GPC and, to a lesser extent, PC, are two major storage forms of choline in the placenta. GPC was significantly depleted within $15 \mathrm{~min}$ following placental delivery, while choline was significantly elevated within $30 \mathrm{~min}$ in the maternal placental tissue. However, PC did not show significant decreases until $24 \mathrm{~h}$ following delivery. In addition, glycerol, released from GPC in the production of PC, was significantly elevated in the maternal placental tissue 30 min following delivery. In the fetal tissue, GPC was significantly diminished $1 \mathrm{~h}$ following delivery, while choline was significantly elevated. However, in the fetal placental tissue, PC was significantly diminished at $15 \mathrm{~min}$, and glycerol was not significantly elevated until $24 \mathrm{~h}$ following delivery. This, along with the evidence of elevated GPC in the maternal placental tissue (Table 1), suggests that the maternal surface has greater choline storage and breakdown than the fetal tissue. Another metabolite found to significantly decrease in both the maternal and the fetal surfaces of the placenta is niacinamide (vitamin B3), important in the synthesis of the cofactor nicotinamide adenine dinucleotide (NAD) for glycolysis and cellular respiration. Although it is not known if niacinamide is produced in the placenta or the fetus, it has been reported in the human placenta tissue and could be an important substrate in regulating the TCA cycle [38].

Many metabolites did not show a significant alteration within $1 \mathrm{~h}$ or even $24 \mathrm{~h}$ following delivery. In both maternal and fetal tissues, metabolites that did not show changes within $24 \mathrm{~h}$ following delivery included amino acids (aspartate, asparagine, lysine, taurine, and serine), ketones (3-HB and acetone), pyrimidine and purine degradation intermediates (uridine and inosine), as well as fumarate and creatine. This could be due to the stability of these metabolites in the placental tissue or the breakdown of other metabolic end products to produce a relatively constant concentration.

The maternal tissue displayed a greater sensitivity to metabolic alterations than the fetal tissue collected from the placenta. This could be explained by the greater abundance of metabolites observed in maternal compared to fetal placental tissue (Table 1), which reflects the fact that many of these metabolites are normally transported from the maternal to the fetal compartment via a concentration gradient. However, even for metabolites that did not significantly differ between maternal and fetal placental specimens, including PC and lactate, there were still significant changes before $1 \mathrm{~h}$ following delivery in the fetal placental specimens.

\section{Materials and Methods}

\subsection{Sample Collection}

Thirteen, gravid full-term subjects were identified at the University of Florida Shands Hospital and gave their written, informed consent for participation. The protocol was approved by the Institutional Review Board (IRB) at the University of Florida (UF IRB20150007). The placentas were collected immediately following cesarean delivery, and the tissue specimens were collected from the whole placenta at five time points postdelivery: $(1)<5 \mathrm{~min}(n=6)$; $(2) 15 \mathrm{~min}(n=13)$; (3) $30 \mathrm{~min}(n=13)$; (4) $1 \mathrm{~h}(n=13)$; (5) $24 \mathrm{~h}(n=13)$. The tissue specimens were immediately frozen in liquid nitrogen following collection. The whole placentas were kept at $4{ }^{\circ} \mathrm{C}$ between sampling time points. Tissue specimens were collected from two areas of the maternal (approximately $1 \times 1 \mathrm{~cm}$ area; depth of $1 \mathrm{~cm}$ ) and fetal surfaces (approximately $1 \times 1 \mathrm{~cm}$ area; depth of $0.3 \mathrm{~cm}$ ) of each placenta at each time point, resulting in 24 total specimens for the $<5$ min time point and 52 total specimens for all other time points. For five fetal and one maternal specimen, there was not enough tissue for metabolomic analysis. Therefore, the total number of specimens for NMR data collection at each time point was as follows: (1) $<5 \mathrm{~min}$ ( $n=12$ fetal, $n=12$ maternal); (2) $15 \mathrm{~min}$ ( $n=24$ fetal, $n=25$ maternal); (3) $30 \mathrm{~min}$ ( $n=25$ fetal, $n=26$ maternal); (4) $1 \mathrm{~h}$ ( $n=25$ fetal, $n=26$ maternal); and (5) $24 \mathrm{~h}(n=25$ fetal, $n=26$ maternal). The samples were stored at $-80^{\circ} \mathrm{C}$ until analysis. 


\subsection{Tissue Preparation}

The placental tissue samples (24.15-192.21 mg; mean $126.21 \mathrm{mg}$ ) were cut on dry ice and washed with ice-cold $0.85 \%$ sodium chloride to remove the excess blood before being placed in prechilled tubes. Five hundred $\mu \mathrm{L}$ of ice-cold 50/50 methanol/water was added to each sample before vortexing for $1 \mathrm{~min}$. Homogenization and sonication methods were compared for metabolite extractions. Equivalent results were observed for both methods and, therefore, sonication was used because of its ability for high-throughput sample preparation. The samples were sonicated for 20 min to extract the metabolites and then spun at $14,000 \mathrm{rcf}$ for $15 \mathrm{~min}$ at $4{ }^{\circ} \mathrm{C}$. Four hundred and fifty $\mu \mathrm{L}$ of supernatant was transferred to a new microcentrifuge tube and concentrated overnight using a CentriVap Benchtop Vacuum Concentrator (Labconco, Kanas City, MO, USA). The samples were frozen at $-80{ }^{\circ} \mathrm{C}$ until metabolomics analysis.

\subsection{Metabolomic Analysis}

Nuclear magnetic resonance (NMR) spectroscopy was used to identify and quantify the metabolites in the placental tissue. The concentrated tissue specimens were thawed, reconstituted in $600 \mu \mathrm{L}$ of $100 \mathrm{mM}$ sodium phosphate buffer at pH 7.0, and vortexed until the pellets dissolved [39]. The samples were centrifuged at $14,000 \mathrm{rcf}$ for $15 \mathrm{~min}$ at $4{ }^{\circ} \mathrm{C}$ before transferring $590 \mu \mathrm{L}$ into $5 \mathrm{~mm}$ NMR tubes (Bruker Biospin, Billerica, MA, USA). The samples were analyzed on an Avance III HD $600 \mathrm{MHz}$ Bruker NMR spectrometer equipped with a Bruker SampleJet cooled to 5.6 ${ }^{\circ} \mathrm{C}$. Data were acquired using a one-dimensional (1D) experiment with $\mathrm{T}_{2}$ filter using Carr-Purcell-Meiboom-Gill (CPMG) pulse sequence with water presaturation for metabolite quantitation and two-dimensional (2D) ${ }^{1} \mathrm{H}-{ }^{13} \mathrm{C}$ heteronuclear single quantum correlation (HSQC) and HSQC-TOCSY (HSQC-total correlation spectroscopy) for metabolite identification. A total of 38 metabolites were identified using Bruker AssureNMR software (Bruker Biospin, USA) with BBiorefcode metabolite database and COLMARm [40]. The metabolites were assigned a confidence level ranging from 1 to 5 , with 5 being the highest. The scale is defined as follows: (1) putatively characterized compound classes or annotated compounds, (2) matched to literature and/or 1D BBiorefcode compound (AssureNMR), (3) matched to HSQC (AssureNMR), (4) matched to HSQC and validated by HSQC-TOCSY (COLMARm), and (5) validated by spiking the authentic compound into sample. The metabolite confidence levels are reported in Table S1. The spectra were processed using Bruker Topspin 3.6 software and in-house MATLAB scripts. All raw and processed data is available on the Metabolomics workbench (http:/ / www.metabolomicsworkbench.org/), along with detailed experimental NMR and analysis methods.

\subsection{Statistical Analysis}

The data were normalized using probabilistic quotient normalization (PQN) and Pareto-scaled, before statistical analysis [41,42]. Multivariate analyses of processed spectra were performed using in-house MATLAB scripts (https:/ / github.com/artedison/Edison_Lab_Shared_Metabolomics_UGA). Orthogonal signal correction partial least squares discriminant analysis (OSC-PLSDA) was conducted using the PLS Toolbox for MATLAB (Eigenvector Research Inc., Manson, WA, USA) to determine metabolites that differed between the maternal and fetal surfaces of the placenta [43]. Partial least squares discriminant analysis (PLS-DA) was used to identify metabolites that differed between time points [44]. The principal component analysis (PCA) scores plots are shown in Figures S1-S3. Univariate statistics were performed on metabolite concentrations of PQN-normalized spectra, and all $\mathrm{p}$-values were subject to false discovery rate using the Benjamini-Hochberg method [45]. A Student's $t$-test with an FDR-correction was used to determine significant metabolites (FDR-corrected, $p<0.05$ ) that differed between the maternal and fetal tissue specimens. A one-way ANOVA was used to determine the metabolites that differed between time points in maternal and fetal specimens 
(FDR-corrected, $p<0.05$ ). A Tukey-Kramer post-hoc analysis was used to determine which time points significantly differed.

\section{Conclusions}

In this study, we show significant metabolic differences between tissue collected from the maternal surface of the human term placenta and that collected from the fetal surface. These results will facilitate future studies that could lead to a better understanding of human placental biology and of how it is disrupted by metabolic diseases such as diabetes or hypertension during pregnancy. In addition, we revealed that these tissue types have distinct profiles of metabolites at the four sampling times following cesarean delivery and that many metabolites remain stable in the fetal placental tissue up to $1 \mathrm{~h}$ following cesarean delivery. This challenges previous literature indicating that the immediate processing of placental specimens is necessary to see significant metabolite alterations [23]. Our study is limited, in that we did not separate the maternal and fetal tissues microscopically in order to assure rapid processing at the first time points. Future studies are needed to more completely divide these tissue types to gain a more complete metabolic profile of the human placenta and to evaluate these metabolic changes in placentas from women in labor, as the onset of labor is likely to also induce changes in the placenta metabolome prior to delivery. However, the information presented here reveals that sampling from just the maternal or the fetal surfaces of the placenta could lead to the loss of valuable metabolic information, and future studies should include both maternal and fetal tissue specimens to gain a better understanding of how placental metabolism is altered as a consequence of maternal or fetal complications during pregnancy.

Supplementary Materials: The following are available online at http://www.mdpi.com/2218-1989/8/1/10/s1. The following are in the attached Supplementary Material document: Figures S1-S5, Tables S1-S3.

Acknowledgments: This study was supported by NIH training grants TL1TR001428 and T32HL083810, the Georgia Research Alliance, and the University of Georgia Office of Research for support. We would also like to thank the members of the Edison, Keller-Wood, and Atkinson laboratories for their resources and expertise, and Steven Robinette for the MATLAB Metabolomics Toolbox.

Author Contributions: Jacquelyn M. Walejko, Anushka Chelliah, and Anthony Gregg conceived and designed the experiments; Jacquelyn M. Walejko and Anushka Chelliah collected the specimens; Jacquelyn M. Walejko prepared the samples and conducted the metabolomics and statistical analyses; Jacquelyn M. Walejko, Arthur S. Edison and Maureen Keller-Wood interpreted the data; Jacquelyn M. Walejko wrote the paper with input from all authors.

Conflicts of Interest: The authors declare no conflict of interest.

\section{References}

1. Carter, A.M. Placental oxygen consumption. Part I: In vivo studies-A review. Placenta 2000, 21, S31-S37. [CrossRef] [PubMed]

2. Bell, A.W.; Kennaugh, J.M.; Battaglia, F.C.; Makowski, E.L.; Meschia, G. Metabolic and circulatory studies of fetal lamb at midgestation. Am. J. Physiol. 1986, 250, E538-E544. [CrossRef] [PubMed]

3. Aldoretta, P.W.; Hay, W.W. Effect of glucose supply on ovine uteroplacental glucose metabolism. Am. J. Physiol. 1999, 277, R947-R958. [CrossRef] [PubMed]

4. Timmerman, M.; Chung, M.; Wilkening, R.B.; Fennessey, P.V.; Battaglia, F.C.; Meschia, G. Relationship of fetal alanine uptake and placental alanine metabolism to maternal plasma alanine concentration. Am. J. Physiol. 1998, 275, E942-E950. [CrossRef] [PubMed]

5. Cetin, I.; Marconi, A.M.; Corbetta, C.; Lanfranchi, A.; Baggiani, A.M.; Battaglia, F.C.; Pardi, G. Fetal amino-acids in normal pregnancies and in pregnancies complicated by intrauterine growth-retardation. Early Hum. Dev. 1992, 29, 183-186. [CrossRef]

6. Chung, M.; Teng, C.; Timmerman, M.; Meschia, G.; Battaglia, F.C. Production and utilization of amino acids by ovine placenta in vivo. Am. J. Physiol. 1998, 274, E13-E22. [CrossRef] [PubMed]

7. Carter, B.S.; Moores, R.R.; Teng, C.; Meschia, G.; Battaglia, F.C. Main routes of plasma lactate carbon disposal in the midgestation fetal lamb. Biol. Neonate 1995, 67, 295-300. [CrossRef] [PubMed] 
8. Cetin, I.; Ronzoni, S.; Marconi, A.M.; Perugino, G.; Corbetta, C.; Battaglia, F.C.; Pardi, G. Maternal concentrations and fetal-maternal concentration differences of plasma amino acids in normal and intrauterine growth-restricted pregnancies. Am. J. Obstet. Gynecol. 1996, 174, 1575-1583. [CrossRef]

9. Chien, P.F.W.; Smith, K.; Watt, P.W.; Scrimgeour, C.M.; Taylor, D.J.; Rennie, M.J. Protein-turnover in the human fetus studied at term using stable-isotope tracer amino-acids. Am. J. Physiol. 1993, 265, E31-E35. [CrossRef] [PubMed]

10. Marconi, A.M.; Paolini, C.L.; Stramare, L.; Cetin, I.; Fennessey, P.V.; Pardi, G.; Battaglia, F.C. Steady state maternal-fetal leucine enrichments in normal and intrauterine growth-restricted pregnancies. Pediatr. Res. 1999, 46, 114-119. [CrossRef] [PubMed]

11. Paolini, C.L.; Marconi, A.M.; Ronzoni, S.; Di Noio, M.; Fennessey, P.V.; Pardi, G.; Battaglia, F.C. Placental transport of leucine, phenylalanine, glycine, and proline in intrauterine growth-restricted pregnancies. J. Clin. Endocrinol. Metab. 2001, 86, 5427-5432. [CrossRef] [PubMed]

12. Bax, B.E.; Bloxam, D.L. Energy metabolism and glycolysis in human placental trophoblast cells during differentiation. Biochim. Biophys. Acta 1997, 1319, 283-292. [CrossRef]

13. Aagaard, K.; Ma, J.; Antony, K.M.; Ganu, R.; Petrosino, J.; Versalovic, J. The placenta harbors a unique microbiome. Sci. Transl. Med. 2014, 6, 237. [CrossRef] [PubMed]

14. Winn, V.D.; Haimov-Kochman, R.; Paquet, A.C.; Yang, Y.J.; Madhusudhan, M.S.; Gormley, M.; Feng, K.T.V.; Bernlohr, D.A.; McDonagh, S.; Pereira, L.; et al. Gene expression profiling of the human maternal-fetal interface reveals dramatic changes between midgestation and term. Endocrinology 2007, 148, 1059-1079. [CrossRef] [PubMed]

15. Uuskula, L.; Mannik, J.; Rull, K.; Minajeva, A.; Koks, S.; Vaas, P.; Teesalu, P.; Reimand, J.; Laan, M. Mid-gestational gene expression profile in placenta and link to pregnancy complications. PLoS ONE 2012, 7, e49248. [CrossRef] [PubMed]

16. Horgan, R.P.; Broadhurst, D.I.; Dunn, W.B.; Brown, M.; Heazell, A.E.; Kell, D.B.; Baker, P.N.; Kenny, L.C. Changes in the metabolic footprint of placental explant-conditioned medium cultured in different oxygen tensions from placentas of small for gestational age and normal pregnancies. Placenta 2010, 31, 893-901. [CrossRef] [PubMed]

17. Dunn, W.B.; Brown, M.; Worton, S.A.; Crocker, I.P.; Broadhurst, D.; Horgan, R.; Kenny, L.C.; Baker, P.N.; Kell, D.B.; Heazell, A.E. Changes in the metabolic footprint of placental explant-conditioned culture medium identifies metabolic disturbances related to hypoxia and pre-eclampsia. Placenta 2009, 30, 974-980. [CrossRef] [PubMed]

18. Van Patot, M.C.T.; Murray, A.J.; Beckey, V.; Cindrova-Davies, T.; Johns, J.; Zwerdlinger, L.; Jauniaux, E.; Burton, G.J.; Serkova, N.J. Human placental metabolic adaptation to chronic hypoxia, high altitude: Hypoxic preconditioning. Am. J. Physiol. Regul. Integr. Comp. Physiol. 2010, 298, R166-R172. [CrossRef] [PubMed]

19. Heazell, A.E.P.; Brown, M.; Dunn, W.B.; Worton, S.A.; Crocker, I.P.; Baker, P.N.; Kell, D.B. Analysis of the metabolic footprint and tissue metabolome of placental villous explants cultured at different oxygen tensions reveals novel redox biomarkers. Placenta 2008, 29, 691-698. [CrossRef] [PubMed]

20. Austdal, M.; Thomsen, L.C.V.; Tangeras, L.H.; Skei, B.; Mathew, S.; Bjorge, L.; Austgulen, R.; Bathen, T.F.; Iversen, A.C. Metabolic profiles of placenta in preeclampsia using HR-MAS MRS metabolomics. Placenta 2015, 36, 1455-1462. [CrossRef] [PubMed]

21. Chi, Y.; Pei, L.; Chen, G.; Song, X.; Zhao, A.; Chen, T.; Su, M.; Zhang, Y.; Liu, J.; Ren, A.; et al. Metabonomic profiling of human placentas reveals different metabolic patterns among subtypes of neural tube defects. J. Proteome Res. 2014, 13, 934-945. [CrossRef] [PubMed]

22. Mossman, H.W. Comparative morphogenesis of the fetal membranes and accessory uterine structures. Contrib. Embryol. 1937, 26, 129-246. [CrossRef]

23. Serkova, N.; Bendrick-Peart, J.; Alexander, B.; Van Patot, M.C.T. Metabolite concentrations in human term placentae and their changes due to delayed collection after delivery. Placenta 2003, 24, 227-235. [CrossRef] [PubMed]

24. Schneider, H.; Mohlen, K.H.; Challier, J.C.; Dancis, J. Transfer of glutamic-acid across the human-placenta perfused invitro. Br. J. Obstet. Gynaecol. 1979, 86, 299-306. [CrossRef] [PubMed]

25. Sweiry, J.H.; Page, K.R.; Dacke, C.G.; Abramovich, D.R.; Yudilevich, D.L. Evidence of saturable uptake mechanisms at maternal and fetal sides of the perfused human-placenta by rapid paired-tracer dilution-Studies with calcium and choline. J. Dev. Physiol. 1986, 8, 435-445. [PubMed] 
26. Meigs, R.A.; Sheean, L.A. Mitochondria from human term placenta. III. The role of respiration and energy generation in progesterone biosynthesis. Biochim. Biophys. Acta 1977, 489, 225-235. [CrossRef]

27. Swierczynski, J.; Scislowski, P.; Aleksandrowicz, Z.; Zelewski, L. Stimulation of citrate oxidation and transport in human placental mitochondria by L-malate. Acta Biochim. Pol. 1976, 23, 93-102. [PubMed]

28. Pinto, J.; Barros, A.S.; Domingues, M.R.; Goodfellow, B.J.; Galhano, E.; Pita, C.; Almeida Mdo, C.; Carreira, I.M.; Gil, A.M. Following healthy pregnancy by NMR metabolomics of plasma and correlation to urine. J. Proteome Res. 2015, 14, 1263-1274. [CrossRef] [PubMed]

29. Lindsay, K.L.; Hellmuth, C.; Uhl, O.; Buss, C.; Wadhwa, P.D.; Koletzko, B.; Entringer, S. Longitudinal metabolomic profiling of amino acids and lipids across healthy pregnancy. PLoS ONE 2015, 10, e0145794. [CrossRef] [PubMed]

30. Carlson, L.A.; Hardell, L.I. Very low-density lipoproteins in cord blood. Clin. Chim. Acta 1978, 90, $295-296$. [CrossRef]

31. Okada, T.; Yonezawa, R.; Miyashita, M.; Mugishima, H. Triglyceride concentrations in very low-density lipoprotein fraction in cord blood during 32-35 week gestation. Early Hum. Dev. 2011, 87, 451. [CrossRef] [PubMed]

32. Yonezawa, R.; Okada, T.; Kitamura, T.; Fujita, H.; Inami, I.; Makimoto, M.; Hosono, S.; Minato, M.; Takahashi, S.; Mugishima, H.; et al. Very low-density lipoprotein in the cord blood of preterm neonates. Metabolism 2009, 58, 704-707. [CrossRef] [PubMed]

33. Rooney, S.A. Fatty acid biosynthesis in developing fetal lung. Am. J. Physiol. 1989, 257, L195-L201. [CrossRef] [PubMed]

34. Fox, J.T.; Stover, P.J. Folate-mediated one-carbon metabolism. Vitam. Horm. 2008, 79, 1-44. [PubMed]

35. Washburn, S.E.; Caudill, M.A.; Malysheva, O.; MacFarlane, A.J.; Behan, N.A.; Harnett, B.; MacMillan, L.; Pongnopparat, T.; Brosnan, J.T.; Brosnan, M.E. Formate metabolism in fetal and neonatal sheep. Am. J. Physiol. Endocrinol. Metab. 2015, 308, E921-E927. [CrossRef] [PubMed]

36. Zeisel, S.H.; Blusztajn, J.K. Choline and human nutrition. Annu. Rev. Nutr. 1994, 14, 269-296. [CrossRef] [PubMed]

37. Zeisel, S.H. Choline: Critical role during fetal development and dietary requirements in adults. Annu. Rev. Nutr. 2006, 26, 229-250. [CrossRef] [PubMed]

38. Mischel, W. Biogenic amines of the placenta. III. Nicotinic acid and nicotinamide content of mature, immature, normal and pathological human placenta. Z. Geburtshilfe Gynakol. 1957, 148, 149-160. [PubMed]

39. Dona, A.C.; Jimenez, B.; Schafer, H.; Humpfer, E.; Spraul, M.; Lewis, M.R.; Pearce, J.T.M.; Holmes, E.; Lindon, J.C.; Nicholson, J.K. Precision high-throughput proton NMR spectroscopy of human urine, serum, and plasma for large-scale metabolic phenotyping. Anal. Chem. 2014, 86, 9887-9894. [CrossRef] [PubMed]

40. Bingol, K.; Li, D.W.; Zhang, B.; Bruschweiler, R. Comprehensive metabolite identification strategy using multiple two-dimensional NMR spectra of a complex mixture implemented in the COLMARm web server. Anal. Chem. 2016, 88, 12411-12418. [CrossRef] [PubMed]

41. Dieterle, F.; Ross, A.; Schlotterbeck, G.; Senn, H. Probabilistic quotient normalization as robust method to account for dilution of complex biological mixtures. Application in $1 \mathrm{~h}$ NMR metabonomics. Anal. Chem. 2006, 78, 4281-4290. [CrossRef] [PubMed]

42. Eriksson, L.; Johansson, E.; Kettaneh-Wold, N.; Wold, S. Multi-and Megavariate Data Analysis. Principles and Applications, 3rd ed.; Umetrics AB: Umea, Sweden, 2001.

43. Trygg, J.; Wold, S. Orthogonal projections to latent structures (O-PLS). J. Chemom. 2002, 16, 119-128. [CrossRef]

44. Wold, S.; Sjostrom, M.; Eriksson, L. Pls-regression: A basic tool of chemometrics. Chemom. Intell. Lab. Syst. 2001, 58, 109-130. [CrossRef]

45. Benjamini, Y.; Hochberg, Y. Controlling the false discovery rate-A practical and powerful approach to multiple testing. J. R. Stat. Soc. Ser. B Methodol. 1995, 57, 289-300.

(C) 2018 by the authors. Licensee MDPI, Basel, Switzerland. This article is an open access article distributed under the terms and conditions of the Creative Commons Attribution (CC BY) license (http:/ / creativecommons.org/licenses/by/4.0/). 